\title{
gabstracts of geritish and foreigir ofournals.
}

Thyssen on Astasia-Abasia (Arch. de Neurologie, t. xxi.).

The combination of symptoms (syndrome) about to be con: sidered is first alluded to in a work by Jaccoud, ${ }^{1}$ where it is described as "Ataxia from want of automatic co-ordination." Lebreton" evidently alludes to the same condition in a thesis on Hysterical Paralysis, in these words: "It often happens that the patient, when in the recumbent posture, can execute extensive movements with the legs. But so soon as she is ordered to walk, after taking a few faltering steps the legs begin to fail, and eventually give way under the weight of the body; it would appear as though at a given moment the accumulated store of nervous energy had become exhausted." Some fifteen years later the symptom is described by Charcot and Richer" as a "special variety of motor feebleness of the legs from want of co-ordination in relation to position in rest and progression." Weir Mitchells describes the same condition under the name Hysterical Motor Ataxia (1885.) Erlenmeyer, ${ }^{6}$ Henoch, ${ }^{7}$ and Romei ${ }^{8}$ also allude to it.

It was, however, Paul Blocq ${ }^{9}$ who, in 1888 , made the first exhaustive' study of the condition, and established its independence. From the consideration of cases which came under his own observation, and of previously recorded cases of similar type, he deduced a new pathological state (type morbide), for which he suggested the name Astasia-Abasia, which has been since more or less generally adopted.

In the same year Charcotio again drew attention to the condition, in a girl of 11 years, at the Salpêtrière, and for the first time used the term Astasia-Abasia in describing a case of this affection in a little boy.

More cases were observed and described by Souza-Leite," Paul Berbez,: Grasset, ${ }^{13}$ Berthet, ${ }^{14}$ Salemi Pace, ${ }^{15}$ Brunon, ${ }^{16}$ and Charcot. ${ }^{17}$ Further additions to the literature of the subject were made by Fr. Helfer ${ }^{18}$ (a case of Astasia-Abusia following on Influenza); by Ladame, ${ }^{19}$ (a case in which the affection was

voL. XrV. 
paroxysmal). Professor Binswanger ${ }^{20}$ has more recently contributed a remarkable paper entitled "Ueber psychisch bedingte Stœrungen des Stehen und des Gehen." Finally, we must mention Moebius' contribution."1

The following is a brief account of the author's cases.

CASE I. (Jan. 1888.) -A girl of 11 years; epileptic since three years, trouble in walking of same date. Walking became impossible in November, 1889 , after an attack of typhoid fever, but recovered partially. When first seen standing and walking were accompanied by marked staggering (without giddiness). On the other hand, the child could alway's hop, skip, or go on all fours without any difficulty. Examination of the legs when sitting revealed nothing abnormal-no anæsthesia, no incoordination. It had been noticed on several previous occasions that after an epileptic seizure there was a decided narrowing of the field of vision, and a marked improvement in walking for a day or two. On February 22nd, a few hours after a seizure, walking was almost natural, the child only staggering, or rather swaying a little, when turning to the right or left. Closing the eyes did not aggravate the unsteadiness. She continued to hop. with perfect ease. The patient was subsequently lost sight of.

CASE II. (1888.)-A girl of $12 \frac{1}{2}$ years, of neuropathic stock. She was seized in 1887 with giddiness, vomiting and headache, accompanied by spinal hyperæsthesia of such severity as to suggest cerebro-spinal meningitis. In July, 1888, her mother noticed disordered movements of the legs when she attempted to. make her stand. About the same time she developed convulsive seizures, preceded by a cephalic aura, with tendency to general contracture. In October following, the patient was seized with unconsciousness whenever the dorso-lumbar portion of the back of her couch was removed, or when it was attempted to make her stand up. It sufficed to sit the child up with the back supported, or to lay her flat on her back, for consciousness to return at once. When sitting up and conscious she is able to move her legs without inco-ordination whilst her eyes are open, but with closed eyes no movement of the legs is possible. During a stay at the seaside she has been able to bathe and swim, in the prone position, without losing consciousness. She spends the day in a wheeled chair with treadles, in which she moves about with ease and rapidity. She presents several hysterogenetic areas which are tender on pressure-ovarian, mammary, spinal, facial and vertical. As a result of treatment by douches and isolation her condition began to improve in 1889 , and after six months of functional impotence 
the child began to walk again, at first with a tottering gait, but eventually without difficulty.

CAsE III.-Miss G. C., aged 19 ycars, came to the Salpêtrière on October 28th, 1888. She has a strong neurotic family bistory. She stated that she had for some time been liable to attacks of weakness (faiblesses) when crossed in any way. Since six months she has suffered from weakness of the legs, worse during the last month, and is unable to stand without support. Since one week choreic movements of the face and right arm have been noted. The lower limbs offer a normal resistance to passive movements of flexicn and extension. Muscular power is somewhat diminished on the left side. She leans back in her armchair, and cannot sit up without supporting herself with both arms. She cannot sit up unaided, or rise from the sitting posture. She is unable to stand without support, and even then sways backwards and forwards, and from side to side. When standing she tbrows herself back on the heels, and the upright posture is further interfered with by inco-ordinate movements (mouvements contradictoires) and prevented by the right-sided paralytic chorea. In walking she drags the right foot (typical gait of hysterical hemiplegia). Subsequently the attacks ceased, and the patient was lost sight of.

CASE IV.-Male, aged 26 years. After a four years' residence in Tonkin, where he contracted dysentery, he was admitted to hospital on his return in October, 1889, suffering from cramps in the lumbar region. His condition on November 6th was the following: lumbar pain, paresis, dyæsthesia of legs as low as knees; frequent cramps in legs; some incontinence of urine; exaggeration of knee-jerks; epileptoid trepidation.

At the same time walking was becoming affected, and when ordered to walk be would jump about as though executing a dance. In February of the following year walking had become quite impossible; as soon as his feet touch the ground he springs from toe to heel as if he were on springs. In March he had ceased to attempt to walk. In April there was a marked improvement, and in the following month standing and walking had become possible, though still very saltatory; in July the saltatory movements were daily growing less marked. Dr. Brissaud, who had previous charge of this patient, communicated the following particulars respecting him : "The patient, when he first came under M. Charcot's care, was no longer suffering from Rythmical Saltatory Abasia. But at an earlier period-in January-he had spasmodic seizures, which, however, were in- 
dependent of abasia. When extended the patient would occasionally be seized with rhythmical tremor precisely similar to that which occurred during walking. This tremor, which came on spontaneously at times, and could be provoked by forcible extension of the leg or flexion of the foot, was closely analogous to epileptiform tremor. Sometimes a sudden removal of the bed-clothes sufficed to initiate the tremor in both legs."

In this respect therefore this patient resembled the subjects of saltatory spasm. He was astasic and abasic only because the weight of the body on the soles of the feet was necessary to cause the spasm. As a matuer of fact his attitude when standing and during walking showed no evidence of inco-ordination, but was well under control and not interfered with in any way by the tremors. Gradually the saltatory spasm subsided, and at the present time there only remains some rhythmical abasia which will shortly disappear.

After recording eleven cases of the affection $M$. Blocq goes on to say: "The onset is rather sudden in the majority of cases. After a sudden emotion or slight traumatism the condition comes into existence at once, or more gradually within the space of twenty-four hours. Not rarely at this period it is preceded or accompanied by pains, such as cephalalgia or rachialgia."

In Charcot and Richer's observations (1883) we read as follows: "this condition develops suddenly after an emotion or traumatism." But in connection with a case he demonstrated last year at the Salpêtrière, Cbarcot observes: "the neurasthenic divorders sometimes develop suddenly in response to some determining cause, such as a mild attack of rheumatism in which the physical disturbance is far in excess of the psychical (sic.); or during convalescence from acute disease attended with marked bodily prostration, e.g., enteric fever or protracted labour; or again, after intoxication by carbonic oxide as in the present instance."

In this last trepidation in walking came on twenty-two days after the intoxication and appears to have been determined by his jolting against a passer-by.

In Romei's case a child of 11 years developed astasia and abasia within twenty-four hours oi a fright. Souza-Leite mentions "a small epidemic of Astasia-Abasia" in which three white women, a mulatto, and a negress were affected.

Prof. Henoch has seen it develop slowly in a child of 7 years, from onanism. The patient experienced difficulty in walking, with intermissions for the first eight months, afterwards permanently. 
A lady of 27 years, under the care of B. Salemi Pace, was seized suddenly after a walk, the only discoverable predisposing cause being weak health of several years' duration. In Berthell's case-a girl of 23-the affection followed on hysterical attacks. Binswanger's patient-a business man of j̃ -was seized quite suddenly as he was sitting down to dinner. He recovered after a while, but subsequently the disease re-appeared in an intermittent form. In a second case (æt. 58) by the same observer, the onset was also quite sudden. In his third case the patient, a music master, aged 35, fell down in the street, and on being raised up was astasic and abasic. Overwork is mentioned as a predisposing cause. Ladame mentions the case of a circus rider who felt unwell during a performance, and four days later suddenly lost the power of walking for a few minutes. For the next four years there was no further evidence of astasia-abasia, but for the last twenty years the condition has returned whenever the patient attempted to walk more than a hundred yards. In this case there was a history of privation, unusual fatigue and physical overwork. A girl of ten years observed by Helfer was siezed on attempting to rise from her bed after influenza; she was cured within five months.

In the author's cases the onset has usually been gradual. Of Blocq's eleven cases the onset was sudden in five.

From these data we may conclude that although the onset is sudden in some cases, or attains its full development in the course of twenty-four hours, it is also frequently slow in its evolution, resembling in this the onset of traumatic hysteria.

Persons of all ages appear to be liable to the affection; the majority of the cases belong to the earlier periods of life, but at least three have occurred in elderly persons.

In addition to the cases quoted or related above, in the course of last year five or six adults suffering from the condition have come under observation at the Salpêtrière. Sex and race do not appear to act as predisposing causes.

Hereditary taint is one of the most constant factors in etiology. Nervous diseases in the parents are of frequent occurrence, and rheumatism is also common. As a matter of fact, the majority of those attacked are predisposed to nervous affections, and this is well borne out by the large majority of the cases quoted above.

As regards symptomatology, all observers draw attention to the fact that the trouble concerns exclusively the combined movements involved in standing and walking, which may be 
interfered with in varying degree, whilst on the other hand, in the horizontal position, the patient retains full muscular power and complete control over his limbs.

This main fact of the integrity of power and control in the horizontal station, and the consequent non-appreciation of the combined muscular efforts required in standing and walking, justify the use of the term "astasia-abasia."

The several features of the condition are demonstrated by making the patients stand up and walk. In some standing and walking are absolutely impossible; as soon as the patient is put on his legs they give way under him, and he falls to the ground; but the same individual will get along perfectly on all-fours, or hopping, or will swim without difficulty. Such a person when supported on both sides will put forward his legs much in the manner of a child learning to walk (Blocq). In others standing and walking are both possible, but attended with great difficulty.

The subjects of this complaint devise all sorts of methods of progression. Some hop along like magpies or push with their feet the chair on which they are sitting. A remarkable case occurred at the Salpêtrière, in which the patient could execute a stage-walk (marche dramatique à très grands pas), but was unable to walk quietly. In many cases associated hysterical manifestations reveal the origin of the trouble, but its existence as a symptom of organic spinal disease is not impossible.

Professor Binswanger affects surprise at Blocq recognising three forms of the affection, according as the power of standing and walking is abolished, diminished or modified, and considers the number of divisions excessive in view of the small number of cases observed, for Binswanger only admits that three of Blocq's eleven cases come within the terms of Charcot's definition of the malady; the troubles observed in the other cases being attributed by him to anæsthesias and hyperæsthesias. Of this more anon. Grasset, taking count of the quality rather than of the degree of aisturbauce, describes ihree types, according as the trouble is due to.weakness to inco-ordination or to rbythmical movements (rhythmical choreic type).

Charcot, in his lecture (1889), adopts the following division :Abasia. $\left\{\begin{array}{l}\text { Paralytic } \\ \text { Ataxic }\end{array}\right.$ $\{$ Choreiform,

according, as standing and walking are impossible, or ataxic, or attended by tremor or choreiform movements. This table roughly indicates the chief heads under which the doubtless 
numerous clinical varieties of this affection will naturally group themselves (Charcot). Ladame's case already introduces a complication, and necessitates the addition of a sub-division for paroxysmal astasia-abasia. Moreover, Brissaud's case does not come within any of the existing groups. The author suggests the following classification :

Astasia-
Abasia. $\left\{\begin{array}{l}\text { Paroxysmal } \\ \text { Continuous }\end{array}\left\{\begin{array}{l}\text { Paraplegic } \\ \text { Ataxic }\end{array}\left\{\begin{array}{l}\text { Tremulous or Trepidating, } \\ \text { Choreiform, } \\ \text { Saltatory, }\end{array}\right.\right.\right.$ which may have to be further amplified.

In connection with Souza-Leite's observations, Biuswanger maintains the necessity of submitting all recorded cases to a searching criticism, and points out the dangers which may arise from describing a disease in terms of its most striking symptom. The author admits that the two cases in question differ somewhat from the types above laid down, but thinks that Binswanger's objection is fairly met by these words of Charcot: "you must not expect to meet in this domain, or in any other indeed, with pure forms or perfect types."

To Blocq and Grasser, amongst others, is due the credit of having differentiated these symptoms of astasia-abasia from associated conditions, and of having demonstrated that these latter are not the cause of the troubles we are here considering.

It is well known that in many cases of perverted sensibility of the lower limbs the gait is in no wise affected. Moreover, it. is not easy to see why sensory troubles, when present, should only affect the mechanisms of normal walking, leaving intact the mechanisms involved in other modes of progression. Sensory troubles when they co-exist are therefore to be considered as hysterical manifestations and not the real cause of the abasic phenomena. As regards differential diagnosis : the inco-ördination in tabes dorsalis and Friedreich's disease attends. all movements of the lower limbs. The hysterical ataxia of. Briquet and Lasèque occurs only when the eyes are closed. In hysterical paraplegias with complete muscular relaxation and. impotence the paralysis is equally marked in the recumbent position. The muscular spasms of rhythmical chorea are characterised by their cadence and regularity. In the reflex saltatory convulsion of Bamberger, spasmodic paralysis, exaggerated reflexes and epileptoid trepidation are prominent symptoms. Charcot and Blocq have put forward to explain the phe- 
nomenon an ingenious psychological hypothesis which has been opposed by Binswanger and criticised adversely by Mœbius. The pathogeny of the French authors is based on our knowledge of the way in which acquired movements become organised. The greater part of the centres for combined muscular movements such as standing, walking, running, swimming, the playing of various musical instruments, \&c., are localised in the brain and spinal marrow. On their hypothesis the spinal centre contains the "materiel d'execution," and is set going by the corresponding cortical céntre, by the "psychological memory," which determines the kind of impulse necessary to produce the required movement. For standing and walking, which are slow of acquisition, Blocq postulates the existence of differentiated cortical cellular groups which are put in relation by special commissural fibres with corresponding groups of cells in the spinal centres. These cortical groups initiate the stimulus in response to which the spinal centres act automatically. These hypotheses have received a certain amount of experimental confirmation, notably from the observation of automatic movements (flying, swimming, \&c.), of certain animals after decapitation. Saleni Pace is of opinion that the cord playe a preponderant part in the causation, and in his own case came to the conclusion that there was a peculiar and partial modification of function in the spinal cord characterised by "dynamic and static motor amnesia." The author is inclined to adopt the views of Blocq, who develops Charcot's ideas, the hypothetical nature of which is fully recognised. The several mechanisms concerned in the performance of walking, standing; jumping, \&c., probably contain two centres, or differentiated cellular groups, the one cortical, the other spinal, which are connected by commissural fibres. The spinal group, without doubt the more complex of the two, governs automatic unconscious execution of the co-ördinated movements necessary to the accomplishment of each function; whereas the cortical group has the relatively simple duty of the voluntary issuing of orders to initiate, accelerate, slacken, or arrest the activity of the spinal group. In other words, the psychological memory of the acts necessary to set going or to check the nervous apparatus are Iocated in the cortical centre, whilst the organic memory which presides over and controls all the details of the prescribed movements has its seat in the spinal centre. Hence in each case the question arises whether the disturbing cause of normal function is to be sought in the encephalon or in the spinal cord. 
It is commonly known that fright may cause paralysis of the legs; and fright is precisely one of the determining causes of astasia-abasia, which would thus be an emotional paralysis succeeded by an auto-suggestion of motor impotence. An inhibition of the cortical or spinal centres controlling standing and walking, would serve to explain the mechanism of such a process. Blocq comes to the conclusion that the change is purely dynamic, but still is localised in the nervous centres in such a manner as to give rise clinically to symptoms identical with those due to organic lesion of the same area. These very simple and ingenious hypotheses Bloeq has been able to verify experimentally by suggestion.

After excluding the cases which present muscular contractions, trepidation and clonic contractions capable of disturbing the functions of standing and walking, together with those in which pain may have prevented movement, Binswanger places the few remaining cases in the large class of "Zwangvorstellungen," or "obsessions," or under the head Hypochondriasis.

The outcome of Binswanger's criticism of the theories of Charcot and Blocq is that he regards astasia-abasia as a state in which the disordered feelings of the organs maintain a hypochondriac preoccupation, or in which well defined causes compel attention to be fixed suddenly and exclusively on an imaginary motor or static impotence.

In order to explain the "obsession," (hypochondrische vorstellungskreise) with which these patients are seized, according. to his view, this author quotes Spinoza; the manner of thought of these patients appears to be strongly influenced by their melancholic turn of mind which is in turn kept alive by the abnormal state of their viscera. He is unable to see what objections there are to classing "obsession" as a symptom of hysteria, since in both conditions bodily action is powerfully influenced by imagination and vice versá.

The author maintains, however, that a line can be drawn between "emotive paralysis" or "paralysis dependent on idea" which occurs in persons of hysterical diathesis as a result of traumatism, preoccupation, or emotion, on the one hand, and " obsession" pure and simple on the other, which affects quite a different category of neuropathic individuals.

The only point in common between the two states is that in both the disturbance is of a psychopathic order. Nevertheless, without insisting on the considerable clinical divergence in the two conditions, attention may be drawn from a psychological. 
stand-point, to the essential difference between the mental troubles in the two cases.

Whereas the hypochondriac is "attentive" even to the point of "obsession" the hysteric is essentially absent-minded. The one concentrates all his faculties on his disease, which is the reason why suggestion is powerless in his case; the other takes no heed of his complaint, and is for that reason generally accounted so favourable a subject for treatment by suggestion. Astasia-abasia is an unconscious, obsession a conscious process.

Mœbius clearly recognises the need of distinguishing between the "inability to will to stand" of the hysteric, and the fear of falling of the subject of "obsession." The "I cannot" of the former is in reality "I cannot will to." As showing the effect of "loss of power to will," when Blocq told a hypnotised subject "you have lost the power of walking," he caused a total loss of motor power; but when he said to him "you no longer know how to walk," the loss of power amounted only to inco-ördination. From another point of view a sort of experimental realisation of abasia lends support to Blocq's theory. It was noted by Steiner that after removal of one of the cerebral hemispheres of the dogfish, the animal swims in a circle. If it is then allowed to pursue this abnormal (abasic) mode of progression for some time, its lower centres become organised in such a way that, after removal of the other hemisphere, the same animal still continues to swim in a circle. .

Mœbius justly observes that the hysteric is conscious that he cannot walk without knowing the reason why, whereas the hypochondriac cannot understand why he is afraid to walk. Again agoraphobia may develop concurrently with neurasthenia, and the latter condition is frequently associated with hysteria, so that the two conditions may co-exist in the same person; it might happen, therefore, that after the sudden disappearance of astasia-abasia, agoraphobia which is always more slow to disappear, would persist alone.

' Jaccoud.-Paraplégie et ataxic du mouvenzent, page 653, Paris, 1864. . Thèse de Paris, 1868. 'Charcot et Richer.-Sıdi una formà d'impotenza motrice degli arti inferiori per diffetto de coordinazione (Medecina contemporanea, 1883, p. 6, no. 1.) See also Charcot: 'Lezioni cliniche dello anno scholestico, 83-84, relatte del dotr Millotti, Milano, 1885. 'Weir Mitchell.-Lect. of diseases of the nervouts system especial in women.' (Philadelphia, 1885, p. 39). -s Erlenmeyer.-Ueber statische Rcflexkrampf, 1886, Leipzig. 'Henoch.Hysteric des enfants, Paris, 1885. (Translation.) ' Dr. Serafino Romei.Paraplegia infantile nel solo atto della ambulatione. (Gazetta degli ospitali, no. 76, p. C05.) 'Paul Blocq._-Sur une affection earactériséc par de l'astasie et 
de l'abasie, Paris, 1888. Archives de Neurologie, no. 43-44. ${ }^{10}$ Charcot.-Leçons du Mardi, 24 janvier, 1888. "Souza Leite.-Reflexions à propos de certaines maladies nerveuses observées dans la ville de Salvador: faits d'ataxie et d'abasie. Progrès medical, XVI., Paris, 1888. "2 Paul Berbez.-Gazette hebdomadaire, 30 novembre, 1888. ' 13 J. Grasset.-Leçons sur un cas d'hystérie male avec astasie-abasie. Montpellier méd., mars, 1889. "Berthet.-Sur un cas d'astasic et d'abasie. (Lyon méd., juillet, 1889.) is Salemi Pace.Amnesia parriale spinale. Gazetta Sicula, Anno IX., p. 182. "Brunon.Normandie médicale, 1889. "Charcot.-Leçons du Mardi à la Salpêtrière, 1888-1889, 5 mars. 's Fr. Helfer._Jahrb. CCXXVI., p. 112. Med. Gescllschafft zu Leipzig. ${ }^{19}$ Ladame.-Arch. de Neurologie, XIX., p. 40, 1890. ${ }^{20}$ Prof. Dr. Otto Binswanger.-Berl. klin Wochenscrift, 1890, no. 21.-Aus der psychiatrischen Klinik zu Jena. " Mœbius.-Leber Astasic-abasie, 1889.

W. Pasteur, M.D.

Current Nerye Anatomy and Physiology. By Alex Hill, M.D., Master of Downing College, Cambridge. ${ }^{\mathrm{T}}$

P ERIOdical.

1. Journal of Comparative Neurology. (Robert Clarke \& Co., 63, W. Fourth Strect, Cincinnati, U. S. A. Price $\$ 3.00$ per annum).

Since the last collection of abstracts was published in Brain, a new journal, devoted to Comparative Neurology, has made its appearance. It is to be published quarterly, and the Editor, whose work, as shown by the first two numbers, gives an excellent promise for the future, undertakes to supply his readers with lists of current neurological literature, resumés of important papers and synopses of those of less general interest. The titles of the papers which appear in the first two numbers are given below, but as they only reached us when this number of Brain was passing through the press it was impossible to abstract their contents.

\section{ANaTomy.}

\section{Certain Recent Researches into the Anatomy of the Central Neryous System. WaLdeyer (Berliner klin. Wochenschr., July 13, 1891, p. 691).}

It may be interesting if this short summary is translated in extenso.

"The investigations under discussion were opened by the record breaking work of Golgi, in Pavia, and carried further especially by S. Ramón y Cajál in Barcelona and by Kolliker. To these must be added the embryological observations of His,

I It is hoped that the retrospect for 1891 may be completed in the Spring Number. The abstracts now given are not necessarily prior to many which will appear in the complete retrospect. 